\title{
Diferential Diagnosis between Esophageal Granuloma and Pulmonary Metastasis
}

\author{
Stéfane Valgas Teixeira', Fernanda Camargo Nunes ${ }^{2}$, Gleidice Eunice Lavalle ${ }^{3}$, \\ Rúbia Monteiro de Castro Cunha ${ }^{4}$, Paula Mayer Costa $^{3}$ \& Rubens Antônio Carneiro ${ }^{5}$
}

\begin{abstract}
Background: Spirocercosis is a parasitic infection caused by Spirocerca lupi. This pathology affects canid carnivores, especially domestic dogs. Early diagnosis has been proven challenging and most infected animals are diagnosed when disease is in advanced stage. Exams such as computed tomography scans or radiographs can aid in disease confirmation. Radiographic exam frequently reveals the presence of a mass located in mediastinal region, which can be erroneously diagnosed as pulmonary mass. The aim of this study was to report the differential diagnosis between paraesophageal granuloma, possibly due to spirocercosis, and pulmonary metastasis in a dog with a history of neurofibrosarcoma.

Case: A 8 year-old male Cocker Spaniel dog, weighing $17.4 \mathrm{~kg}$, was presented with anterior limb suspension and a recurrent nodule of $2.0 \mathrm{~cm}$ diameter, located on the main pad, with previous diagnosis of neurofibrosarcoma (malignant Schwannoma). Routine evaluation work-up included thoracic radiographs and abdominal ultrasound for clinical staging, electrocardiogram, complete blood count (CBC), coagulogram, renal and hepatic function tests, with results within the normal range for the species. The dog submitted to left anterior limb amputation due to recurrent neurofibrosarcoma in the carpal region. Histopathological exam confirmed recurrent neurofibrosarcoma without vascular invasion. Considering neoplasm biological behavior and clean surgical margins, only routine follow-up was established, with clinical exams. The dogwas presented to the Veterinary Hospital five months after surgical treatment and it was presented with fever, prostration, and history of vomiting. Radiographic exam showed a circumscribed mass in caudal mediastinal area. Computed tomography scan was performed to best evaluate the mass and the result was compatible with paraesophageal abscess. These findings were consistent with paraesophageal abscess with necrotic center caused by Spirocerca lupi; however, it was not possible to exclude the possibility of lymph node neoplasms, with necrotic center/secondary abscess. Coproparasitological test result was negative; however, considering the endemic aspect of spirocercosis, the dog was treated with Ivermectin was given orally, for 14 days, and complete remission was observed at the end of the treatment, without any significant side effects. Discussion: Spirocercosis has a worldwide dissemination, limited only by the presence of intermediate host. In endemic regions, prevalence in dogs may be $100 \%$. Diagnosis may be challenging, especially in atypical cases and in patients with complications. Spirocercosis diagnosis may be achieved from therapeutic response in typical cases, with suggestive radiographic and tomographic findings. Radiologic and tomographic findings in this case were similar to common spirocercosis findings. Follow up by a veterinary oncologist is of utmost importance; an unprepared veterinarian could indicate thoracotomy or even euthanasia. Even though coproparasitological exam was negative, the endemic aspect of spirocercosis in the area supported the decision for treatment and therapeutic diagnosis. Oncologic patients should be carefully evaluated, for not all pathologies they develop after a neoplasm diagnosis are related to cancer. Knowledge of disease biologic behavior is essential to make correct decisions regarding patient health status.
\end{abstract}

Keywords: Spirocerca lupi, granulomas, neurofibrosarcoma.

${ }^{1}$ Mestrado \& ${ }^{2}$ Doutorado, Programa de Pós-graduação em Patologia Geral da Faculdade de Medicina, Universidade Federal de Minas Gerais (UFMG), Belo Horizonte, MG, Brazil. ${ }^{3}$ M.V., Escola de Veterinária (EV), UFMG, Belo Horizonte. ${ }^{4}$ Doutorado, Programa de Pós-graduação em Ciência Animal, EV, UFMG, Belo Horizonte. ${ }^{5}$ Departamento de Clínica e Cirurgia, EV, UFMG, Belo Horizonte. CORRESPONDENCE: S.V. Teixeira [stefanevalgas@ gmail.com - Tel.: +55 (31) 99784-4618]. Escola de Veterinária - UFMG. Avenida Antônio Carlos n. 6627. Bairro Pampulha. CEP $31270-901$ Belo Horizonte, MG, Brazil. 


\section{INTRODUCTION}

Spirocercosis is a parasitic infection caused by a nematode known as Spirocerca lupi $[12,13]$. This pathology affects canid carnivores, especially domestic dogs $[3,8]$. Adult parasites form fibrous nodules of varying sizes on the esophagus, stomach, and aorta walls [2]. Larvae migrate through gastric arteries, reach the celiac artery, and access the aorta in approximately seven days. In three weeks, larvae migrate from the aorta through adjacent tissues and reach esophagus or stomach walls, where they cause fibrous nodule formation [14]. Esophageal nodule growth, especially when located next to the cardia, can cause partial obstruction, leading to dysphagia and gastric discomfort, with regurgitation and vomit [2,3]. Early diagnosis has been proven challenging and most infected animals are diagnosed when disease is in advanced stage $[8,10]$. Radiographic exam frequently reveals the presence of a mass located in mediastinal region, which can be erroneously diagnosed as pulmonary mass $[7,10]$. Pulmonary neoplasms represent the main cancer related cause of death in human and veterinary patients worldwide; although primary lung cancer is relatively uncommon is dogs and cats. Pulmonary metastasis, however, are frequent, especially with specific neoplastic diagnosis. Other neoplasms have elevated local aggressiveness and invasive potential, but have a low to moderate metastatic potential, such as canine soft tissue sarcomas [7]. The aim of this study was to report differential diagnosis between esophageal granuloma, possibly caused by spirocercosis, and a possible neurofibrosarcoma lung metastasis, which was weakly supported due to known neoplasm biologic behavior.

\section{CASE}

A 8 year-old male Cocker Spaniel dog, weighing $17.4 \mathrm{~kg}$, was presented with anterior limb suspension and a recurrent nodule of $2.0 \mathrm{~cm}$ diameter, located on the main pad, with previous diagnosis of neurofibrosarcoma (malignant Schwannoma). Routine evaluation work-up included thoracic radiographs and abdominal ultrasound for clinical staging, electrocardiogram, complete blood count (CBC), coagulogram, renal and hepatic function tests, with results within the normal range for the species. Patient was subjected to left anterior limb amputation at distal humerus, to achieve clean surgical margins. Histopathological exam confirmed recurrent neurofibrosarcoma without vascular invasion. Considering neoplasm biological behavior and clean surgical margins, only routine follow-up was established, with clinical exams, abdominal ultrasound, thoracic radiographs, $\mathrm{CBC}$, renal and hepatic function tests every three months for two years. However, five months after surgery, patient was presented with fever, weight loss, prostration, inappetence and vomiting for two days. Simple and contrast radiographs showed a circumscribed mass, located in caudal mediastinal area, with the center located in T8 region, extending until T9, without contrast uptake (Figure 1).

Considering neoplasm biological behavior and its low metastatic potential, other imaging exams were performed for diagnosis confirmation and treatment planning.

Computed tomography scan was performed to better characterize the mass, using simple and contrasted sequential axial sections of 3 and $5 \mathrm{~mm}$ of the thorax and multiplanar reconstruction. CT scan showed a round mass of approximately $5.1 \mathrm{~cm}$ (width) x 3.3 $\mathrm{cm}$ (height) $\mathrm{x} 4.5 \mathrm{~cm}$ (length) located caudal to main bronchus bifurcation, dorsal to heart, and ventral to descending aorta and esophagus. Following contrast administration, the mass borders were discretely enhanced and in close contact with caudal vena cava. Caudal and accessory bronchi were compressed and the esophagus showed a narrowing adjacent to the mass. The center of the mass had low density (18 HU). A round structure of $0.7 \mathrm{~cm}$ (width) x $0.9 \mathrm{~cm}$ (height) $\mathrm{x}$ $0.9 \mathrm{~cm}$ (length) adjacent to the esophagus on the right side showed soft tissue density and was discretely enhanced after contrast administration (20 HU). These findings were consistent with paraesophageal abscess with necrotic center caused by Spirocerca lupi; however, it was not possible to exclude the possibility of lymph node neoplasms, with necrotic center/secondary abscess (Figure 2a \& Figure 2b).

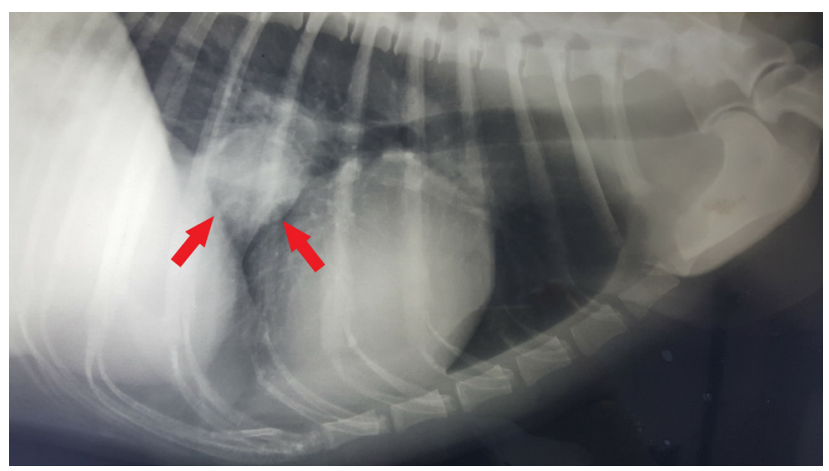

Figure 1. Radiographic image of a mass located in caudal mediastinal area (arrows), with the center located in T8 region, extending until T9 (simple radiography). 


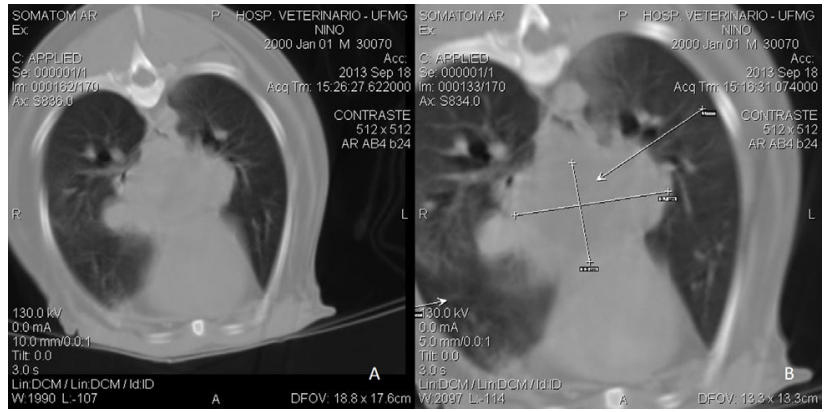

Figure 2. A- Computed tomography (CT) scan with simple and contrasted (IV) sequential axial sections of 3 and $5 \mathrm{~mm}$ of the thorax and multiplanar reconstruction showing a round mass of approximately $5.1 \mathrm{~cm} \mathrm{x} 3.3 \mathrm{~cm} \mathrm{x}$ $4.5 \mathrm{~cm}$. B- Close view of the mass (arrow).

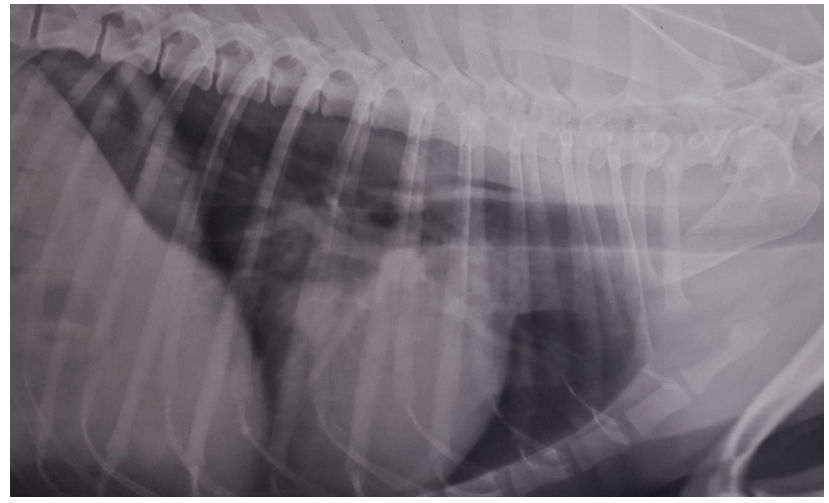

Figure 3. Simple thoracic radiography, showing normal parenchyma.

Coproparasitological test result was negative; however, considering the endemic aspect of spirocercosis in the area of the study, it was decided to treat the patient with ivermectin, $0.2 \mathrm{mg} \cdot \mathrm{kg}^{-1}, \mathrm{PO}, 14$ days (Mectimax Ivermectina $\left.{ }^{\circledR}\right)^{1}$. After treatment, patient showed weight gain, improved appetite and significant reduction of the mass assessed with thoracic radiographic exam. After a month, thoracic radiography showed normal pulmonary parenchyma (Figure 3). Patient overall survival was four years, without complications due to the neoplasm (neurofibrosarcoma).

\section{DISCUSSION}

Spirocercosis has a worldwide dissemination, limited only by the presence of intermediate host. In endemic regions, prevalence in dogs may be 100 $\%$ [9]. Diagnosis may be challenging, especially in atypical cases and in patients with complications. Early suspicion of Spirocerca lupi granuloma is through simple or contrast radiographs [5], with a better definition of the mas with CT scan or endoscopy [3], which was the order followed in the case reported here, including radiography and CT scan. Radiologic and tomographic findings in this case were similar to common spirocercosis findings, according to Dvir et al. [3]: caudal mediastinal mass, centered in T8, with possible extension from T5 to T12. Granulomas can expand and present partially necrotic areas, which was seen on CT scan. Pulmonary metastasis is a common fear for patients with a history of malignant neoplasm, especially when there are suggestive radiographic images, because lung is the main metastatic organ in many neoplastic conditions. However, understanding of disease biological behavior and characteristics allowed questioning metastatic suspicion and determined the need to investigate other possible diagnoses [7].

Follow up by a veterinary oncologist is of utmost importance; an unprepared veterinarian could indicate thoracotomy or even euthanasia. Even though coproparasitological exam was negative, the endemic aspect of spirocercosis in the area supported the decision for treatment and therapeutic diagnosis. Many drugs have been used for spirocercosis treatment and prophylaxis with variable results $[1,3,4,14]$. In the case reported here, ivermectin was given orally, for 14 days, and resulted in complete remission, without any significant side effects. Spirocercosis diagnosis may be achieved from therapeutic response in typical cases, with suggestive radiographic and tomographic findings. Oncologic patients should be carefully evaluated, for not all pathologies they develop after a neoplasm diagnosis are related to cancer. Knowledge of disease biologic behavior is essential to make correct decisions regarding patient health status.

\section{MANUFACTURER}

${ }^{1}$ Agener União - Saúde Animal. União Química Farmacêutica Nacional S/A. São Paulo, SP, Brazil.

Declaration of interest. The authors report no conflicts of interest. The authors alone are responsible for the content and writing of the paper.

\section{REFERENCES}

1 Berry W.L. 2000. Spirocerca lupi esophageal granulomas in 7 dogs: resolution after treatment with doramectin. Journal of Veterinary Internal Medicine. 14: 609-612.

2 Cury M.C. \& Lima W.S. 2002. Helmintos de cães e gatos. Caderno Técnico Veterinária Zootecnia. 39: 12-35. 
3 Dvir E., Kirberger R.M. \& Malleczek D. 2001. Radiographic and computed tomographic changes and clinical presentation of spirocercosis in the dog. Veterinary Radiology and Ultrasound. 42: 119-129.

4 Fox S.M., Burns J. \& Hawkins J. 1988. Spirocercosis in dog. Compendium of Continuing Education of the Practicing Veterinarian. 10: 807-822.

5 Gosling E. \& Gracia A. 1983. Diagnostico precoz y tratamiento de la pirocercosis (Spirocerca lupi). Veterinaria Tropical. 8: 57-69.

6 Liptak J.M. \& Forrest L.J. 2013. Soft Tissue Sarcomas. In: Withrow \& MacEwen's Small Animal Clinical Oncology. 5th edn. Philadelphia: W.B. Saunders Co., pp.356-380.

7 Markovics A. \& Medinski B. 1996. Improved diagnosis of low intwnsity Spirocerca lupi infection by the sugar flotation method. Journal of Veterinary Diagnostic Investigation. 8: 400-401.

8 Mazaki-Tovi M., Baneth G., Aroch I., Harrus S., Kass P.H., Ben Ari T., Zur G., Aizenberg I., Bark H. \& Lavy E. 2002. Canine spirocercosis: clinical, diagnostic, pathologic and epidemiologic characteristics. Veterinary Parasitology. 107: 235-250.

9 Ranen E., Lavy E., Aizenberg I., Perl S. \& Harrus S. 2004. Spirocercosis-associated esophageal sarcomas in dogs. A retrospective study of 17 cases (1997-2003). Veterinary. Parasitology. (30)119: 209-221.

10 Ribeiro V.M. 2004. Controle de helmintos de cães e gatos. Revista Brasileira de Parasitologia Veterinária. 13(Suppl 1): 88-95.

11 Rudolphi C. A. 1809. Entozoorum, sive vermium imtestinalium historia naturalis. Vol.II. P. I-II. Amstelaedami: Sumtibus tabernae librariae et artium. 457: 386.

12 Seneviranta P., Fernando S.T. \& Dhanapala S.B. 1966. Disophenol treatment of spirocercosis in dogs. Journal of the American Veterinary Medical Association 148 (3): 269-274.

13 Soulsby E.J.L. 1986. Spirocerca lupi. In: Soulsby E.J.L. (Ed). Helminths, Arthropods and Protozoa of Domesticated Animals. London: Baillière Tindall, pp.291-294.

14 Van der Merwe L.L., Kirberger R.M, Clift S.,Williams M., Keller N. \& Naidoo V. 2008. Spirocerca lupi infection in the dog : A review. The Veterinary Journal. 176: 294-309. 